\title{
Analisis Teknikal Harga Saham Waskita Karya Tahun 2017 \\ dengan Metode ARIMA
}

oleh :

Wahyuni Windasari S.Si., M.Sc

STIE Putra Bangsa Kebumen

\begin{abstract}
As an investor needs to do an analysis before making a decision either in selling or buying shares. Security analysis consist of two types of analysis, namely tecnical analysis and fundamental analysis. Technical analysis to test wheater historical data will predict stock prices as a consideration to buy or sell an investment's instrument. One type of technical analysis is the ARIMA method. In this research uses daily stock price of WSKT Tbk during 1 Januari-10 Oktober 2017 to predict stock prices the few days. The best ARIMA model to describe WSKT stock price movement is MA(4), with MAE predict data is 480.25.
\end{abstract}

Key words : forecasting, ARIMA, technical analysis, stock prices.

\section{PENDAHULUAN}

Pembangunan infrastruktur dan peningkatan konektivitas di wilayah seluruh Indonesia merupakan salah satu titik pokok pembangunan yang dilakukan pada masa pemerintahan Jokowi-JK. Hal itu tentunya akan berdampak bagi saham-saham yang bergerak di bidang infrastruktur, salah satunya adalah saham Waskita Karya (WSKT). Perusahaan dengan plat merah ini mengklaim bahwa proyek jalan tol merupakan proyek terbanyak yangdikerjakan sepanjang tahun 2017.

Selama tahun pengerjaan 2017, banyak proyek-proyek yang dikerjakan oleh WSKT yang mengalami kecelakan konstruksi. Tercatat pada tanggal 4 Agustus 2017, saham WSKT melemah $0.44 \%$ setelah terjadi kecelakan proyek yaitu jatuhnya tiang penyangga LRT Palembang. Selain itu, runtuhnya badan jembatan tol Bocimi pada tanggal 22 September 2017, mengakibatkan saham WSKT turun $1,05 \%$ pada saat penutupan. Kejadian kecelakan yang cukup banyak selama pengerjaan proyek WSKT ini cukup berpengaruh pada penurunan pergerakan harga saham. Kejadian kecelakan proyek yang berimbas pada penurunan harga saham ini tentunya menjadi hal yang perlu diperhatikan oleh seorang investor.

Sebagai seorang investor perlu melakukan analisis sebelum mengambil keputusan baik untuk menjual maupun membeli saham. Dalam berinvestasi terdapat dua jenis analisis yaitu analisis secara fundamental dan analisis teknikal. Analisis secara fundamental artinya seorang investor melakukan analisis dengan mempelajari tentang faktor fundamental berupa tingkat suku bunga, rasio keuangan, dan neraca. Selanjutnya, analisis teknikal adalah langkah penilaian atas saham suatu perusahaan dengan menggunakan data historis dalam memprediksi harga saham dan pengambilan keputusan sebelum menjual atau membeli saham sebuah perusahaan. Dalam kenyataannya, para investor lebih menitikberatkan pada faktor fundamental dan mengesampingkan faktor teknikal. Atas dasar tersebut maka pada penelitian ini akan dilakukan analisis teknikal untuk menganalisis pergerakan harga saham WSKT sekaligus meramalkan pergerakan saham WSKT beberapa periode ke depan dengan 
menggunakan data historis harga saham harian WSKT.

\section{METODOLOGI PENELITIAN}

\section{Runtun Waktu Stasioner}

Suatu data runtun waktu dikatakan stasioner (mean) jika rata-rata data time series tersebut relative konstan dari waktu ke waktu, atau bisa dilihat tidak ada unsur trend dalam data. Untuk menguji kestasioneritasan data dapat dilihat dari bentuk visual plot data atau dapat dilakukan dengan uji Dickey-Fuller test. Jika nilai mutlak ADF Test Statistik kurang dari nilai mutlak Critical Value, maka dapat disimpilkan data tidak stasioner dalam mean.

\section{Metode Box-Jenkins}

Metode Box-Jenkins atau yang sering disebut ARIMA (Autoregresif Integrated

Moving Average) adalah suatu model yang menggunakan nilai masa lalu dan sekarang dari variabel dependen untuk meramalkan

data jangka pendek. Dalam hal ini, model ARIMA mengabaikan variabel independen dalam membuat keputusan dalam peramalan. Model ARIMA dibagi dalam tiga kelompok yaitu model autoregressive (AR), moving average (MA), dan model campuran atau ARIMA. Secara umum model ARIMA dituliskan dalam persamaan di bawah ini:

$$
(1-B)\left(1-\emptyset_{i}\right) X=\mu^{\prime}+\left(1-\theta_{j}\right) e_{t}
$$

dengan :

$$
\begin{array}{ll}
(1-B) & : \text { Pembedaan pertama } \\
\left(1-\emptyset_{i}\right) X_{t} & : \text { Komponen AR } \\
\mu^{\prime}+\left(1-\theta_{j}\right) t & : \text { Komponen MA. }
\end{array}
$$

\section{Langkah-Langkah Pemodelan ARIMA}

(1) Identifikasi Model

Proses identifikasi dari model dapat dilakukan secara visual dengan menggunakan plot atau alat statistik berupa autokorelasi dan parsial autokorelasi.

(2) Penaksiran Parameter

Salah satu cara penaksiran nilai parameter model adalah dengan menggunakan perbaikan secara iteratif. Cara ini berarti memilih nilai taksiran awal dan kemudian membiarkan program komputer memperhalus penaksiran tersebut secara berulang.

(3) Pengujian Parameter Model

Pengujian parameter dilakukan baik secara parsial ( $t$-test) maupun keseluruhan (overall $F$-test).

(4) Pemilihan Model Terbaik

Untuk menentukan model terbaik dapat digunakan mean absolute error (MAE). Model yang baik adalah model dengan nilai MAE yang terkecil. Adapun nilai MAE diperoleh dari persamaan di bawah ini :

$$
\mathrm{MAE}=\frac{\mid \sum_{t=1}^{n}\left(X_{t}-\hat{X} \mid\right.}{n}
$$

dengan :

$X$ : Nilai sebenarnya pada waktu ke-t

$\hat{X}$ : Nilai dugaan pada waktu ke-t.

(5) Peramalan

\section{HASIL DAN PEMBAHASAN}

\section{Data}

Data yang digunakan dalam penelitian ini adalah data sekunder berupa data harga harian saham WSKT periode 1 Januari 201710 Oktober 2017. Data ini diambil dari finance.yahoo sebanyak 200 data yang kemudian dibagi menjadi dua bagian yaitu 196 data insample dan 4 data outsample.

\section{Analisis Data}

Dalam tahap awal untuk prapemrosesan data dilakukan identifikasi model time series secara sederhana yaitu dengan menggunakan plot. Hal ini digunakan untuk mengetahui ada tidaknya komponen non-stasioneritas baik dalam rata-rata berupa 
trend dan musiman maupun dalam variansi berupa stabilitas data.

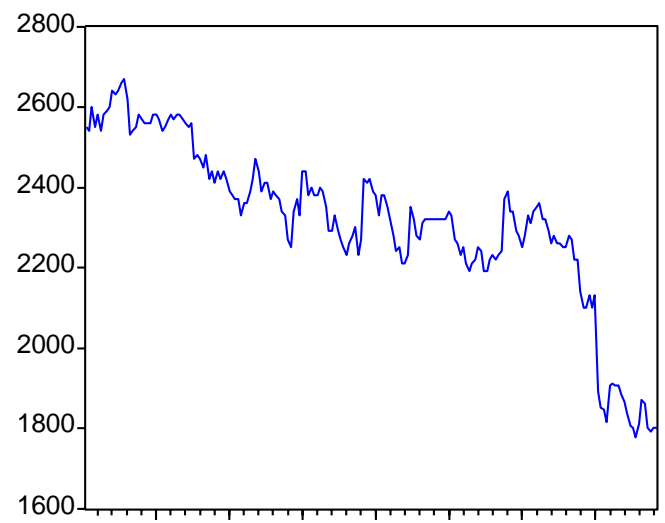

$25 \quad 50 \quad 75 \quad 100125150175$

\section{- WSKT}

Gambar 1. Plot Data Saham Harian WSKT

Dari Gambar 1 di atas tampak terlihat adanya trend kenaikan dan penurunan harga saham WSKT yang menandakan data belum stasioner. Hal ini diperkuat dengan hasil uji ADF dengan nilai Prob $=0.3980>\alpha=0.05$.

\begin{tabular}{|c|c|c|}
\hline \multicolumn{3}{|c|}{ Augmented Dickey-Fuller Unit Root Test on WSKT } \\
\hline $\begin{array}{l}\text { Null Hypothesis: WSKT has a unit root } \\
\text { Exogenous: Constant, Linear Trend } \\
\text { Lag Length: } 0 \text { (Automatic based on SIC }\end{array}$ & $G=14)$ & \\
\hline & t-Statistic & Prob. ${ }^{*}$ \\
\hline Augmented Dickey-Fuller test statistic & -2.362587 & 0.3980 \\
\hline $\begin{array}{ll}\text { Test critical values: } & 1 \% \text { level } \\
& 5 \% \text { level } \\
& 10 \% \text { level }\end{array}$ & $\begin{array}{l}-4.005809 \\
-3.433036 \\
-3.140335\end{array}$ & \\
\hline
\end{tabular}

*MacKinnon (1996) one-sided p-values.

\section{Gambar 2. Output Uji ADF}

Untuk mendapatkan data yang stasioner baik dalam rata-rata maupun variansi, maka perlu dilakukan differencing dan transformasi boxcox. Dalam kasus ini dipilih bentuk transformasi Ln untuk menstasionerkan data harga saham WSKT dalam variansi. Adapun hasil output dari proses pembedaan dan transformasi tersebut diberikan pada Gambar 3 di bawah ini :

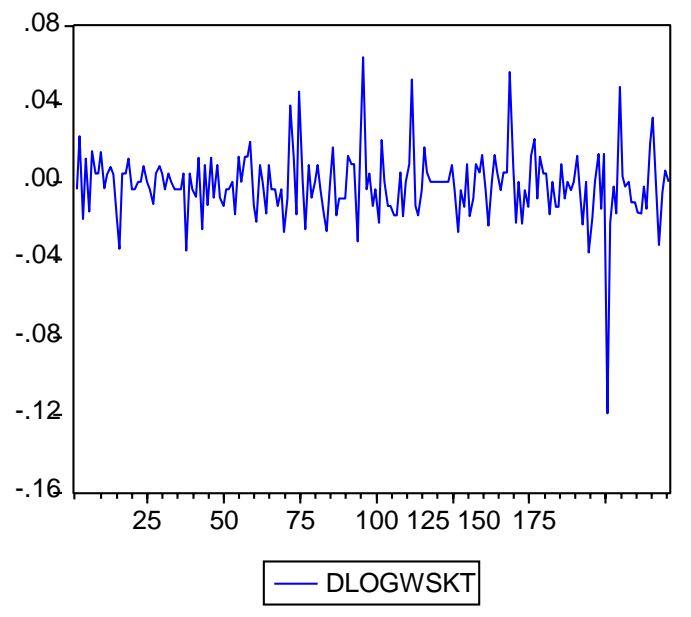

Gambar 3. Plot Hasil Pembedaan dan Transformasi Box-Cox Harga Saham WSKT

Dari Gambar 3, tampak terlihat variansi data relatif lebih stabil dengan nilai rata-rata yang tampak lebih konstan. Kondisi ini menandakan data hasil pembedaan dan transformasi sudah stasioner. Selanjutnya, untuk penentuan model alternatif digunakan plot ACF dan PACF dari data yang sudah stasioner. Adapun hasil output untuk plot ACF dan PACF data diberikan pada Gambar 4 di bawah ini :

\begin{tabular}{|c|c|c|c|c|c|}
\hline \multicolumn{6}{|c|}{ Correlogram of DLOGWSKT } \\
\hline \multicolumn{6}{|c|}{$\begin{array}{l}\text { Date: 04/08/18 Time: } 14: 41 \\
\text { Sample: } 1196 \\
\text { Included observations: } 195\end{array}$} \\
\hline Autocorrelation & Partial Correlation & $\mathrm{AC}$ & PAC & Q-Stat & Prob \\
\hline $1 \mid 1$ & $1 \mid 1$ & 10.003 & 0.003 & 0.0021 & 0.963 \\
\hline 101 & 1 & $2-0.069$ & -0.069 & 0.9474 & 0.623 \\
\hline 101 & 101 & $3-0.053$ & -0.053 & 1.5078 & 0.680 \\
\hline 4 & - 1 & $4-0.134$ & -0.139 & 5.1091 & 0.276 \\
\hline 11 & 11 & 50.003 & -0.005 & 5.1113 & 0.402 \\
\hline $1 \mid$ & $1 \mid 1$ & 60.030 & 0.007 & 5.2901 & 0.507 \\
\hline
\end{tabular}

\section{Gambar 4. Plot ACF dan PACF dari} d $\log ($ WSKT)

Berdasarkan Gambar 4 di atas, tampak terlihat lag kecil yang signifikan ( keluar garis) yaitu pada lag 4, sehingga berdasarkan prinsip parsimony model maka dapat diperoleh model untuk data harga saham WSKT yaitu model AR(4) dan MA(4). Selain itu, dapat juga dipilih model ARMA $(4,4)$ sebagai model alternatif. Adapun hasil rangkuman diagnostik cek untuk ketiga model tersebut diberikan pada Tabel 1 di bawah ini : 
Tabel 1. Rangkuman Model ARIMA

\begin{tabular}{crrr}
\hline & AR(4) & MA(4) & ARMA(4,4) \\
\hline \multicolumn{1}{c}{$a_{4}$} & -0.125 & & 0.268 \\
& $(0.0842)$ & & $(0.4024)$ \\
\multicolumn{1}{c}{$b_{4}$} & & & \\
& & -0.147 & -0.416 \\
SSR & 0.0592 & 0.060 & $(0.1767)$ \\
AIC & -5.231 & -5.236 & 0.0587 \\
SBC/BIC & -5.214 & -5.219 & -5.229 \\
Q(12) & 8.147 & 6.7160 & -5.196 \\
& $(0.700)$ & 0.822 & 5.881 \\
Q(24) & 21.608 & 20.189 & $(0.825)$ \\
& $(0.544)$ & $(0.630)$ & 18.442 \\
& 36.522 & 34.832 & $(0.679)$ \\
Q(36) & $(n 208)$ & $(0.476)$ & $(0.546)$ \\
& & & \\
\hline
\end{tabular}

Dari rangkuman model Arima, terlihat bahwa koefisien AR(4) dan AR(4) serta MA(4) pada model ARMA $(4,4)$ tidak signifikan, dimana nilai $p$-value untuk masing-masing koefisien adalah $0.0842>\alpha=0.05$ dan $p$-value $=0.4024$ serta $p$-value $=0.1767>\alpha=0.05$. Sehingga untuk kedua model ini dikeluarkan dari pilihan model untuk data harga saham harian WSKT. Selanjutnya untuk model MA (4) diperoleh nilai koefisien yang sudah signifikan dengan nilai $p$-value $=0.0417<\alpha=0.05$ dan uji terhadap residual menunjukkan sudah tidak terdapat korelasi serial dalam data. Selain itu, pada kolom SSR dan AIC model MA (4) memiliki nilai yang kecil. Sehingga dapat disimpulkan, model MA(4) adalah model terbaik untuk memodelkan harga saham harian WSKT. Selanjutnya, akan dilakukan peramalan 4 hari ke depan dengan menggunakan model terpilih yaitu MA(4). Untuk plot fitting model diberikan pada Gambar 5 di bawah ini.
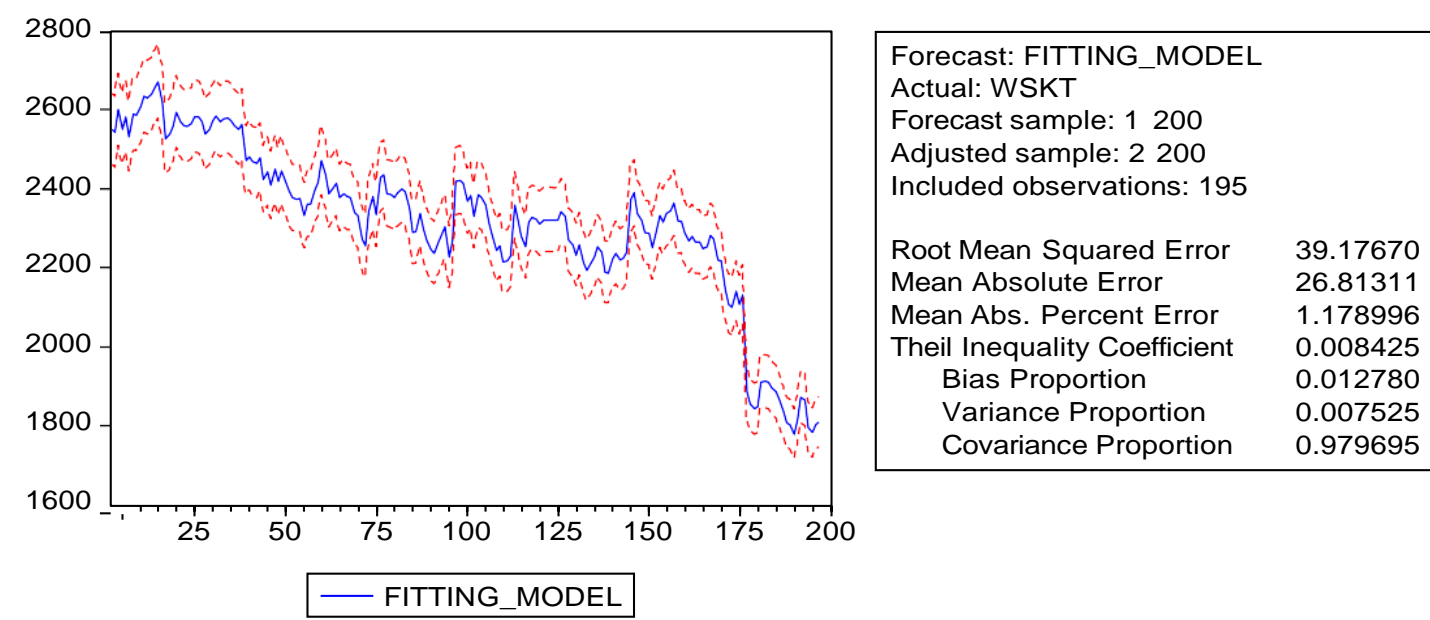

Gambar 5. Plot Fitting Model 
Dari Gambar 5 terlihat bahwa untuk periode 4 hari ke depan, harga saham WSKT mengalami trend kenaikan. Untuk selengkapnya, hasil peramalan dan error model diberikan pada Tabel 2 di bawah ini :

Tabel 2. Hasil Peramalan dan Error Model

\begin{tabular}{|r|c|r|r|}
\hline Tanggal & $\begin{array}{c}\text { Data } \\
\text { Asli }\end{array}$ & $\begin{array}{c}\text { Hasil } \\
\text { Peramalan }\end{array}$ & \multicolumn{1}{|c|}{ Error } \\
\hline $11 / 10 / 2017$ & 1815 & 1809 & 6 \\
\hline $12 / 10 / 2017$ & 1830 & 2550 & 720 \\
\hline $13 / 10 / 2017$ & 1865 & 2550 & 685 \\
\hline $16 / 10 / 2017$ & 2040 & 2550 & 510 \\
\hline \multicolumn{3}{|c|}{ MAE } & $\mathbf{4 8 0 . 2 5}$ \\
\hline
\end{tabular}

\section{KESIMPULAN}

(1) Model MA (4) adalah model terbaik yang menggambarkan pergerakan harga saham WSKT selama periode 1 tahun dan juga mampu untuk menghasilkan nilai peramalan yang baik dengan nilai MAE sebesar Rp. 480,25

(2) Model ARIMA dapat diterapkan oleh para investor untuk melakukan prediksi harga saham jangka pendek artinya apabila terdapat data terbaru maka model ARIMA perlu diujikan kembali.

\section{DAFTAR PUSTAKA}

Gujarati,Damodar. 2004. Dasar-Dasar Ekonometrika. Jakarta:Salemba Empat.

https://finance.detik.com/bursa-dan-valas/d-3876562/mengintip-pergerakan-saham-waskitatiap-kali-ada-insiden-konstruksi. [diakses terakhir pada 10 Oktober, pukul 13.22]

https://finance.yahoo.com/quote/WSKT.JK?p=WSKT.JK [diakses terakhir pada 10 Oktober 2017, pukul 16.25]

Makridakis. 1999.Metode dan Aplikasi Peramalan Jilid I. Jakarta : Binarupa Aksara.

Rosadi,Dedi. 2011.Ekonometrika \& Analisis Runtun Waktu Terapan dengan E-Views. Yogyakarta : ANDI.

Yani, Achmad. 2004. Tesis Analisis Teknikal Harga Saham dengan Metode ARIMA ( Studi Pada IHSG di Bursa Efek Jakarta). Semarang : Undip. 